\title{
Research on the Magnetic Properties TP347H Tubes and its High Temperature Oxidation
}

\author{
ZHANG Huaiyu, a , LIU Baojun ${ }^{1, b}$, DU Haoyang ${ }^{2,3, c^{*}}$,WANG Haijun ${ }^{3, \mathrm{~d} *}$, CUI \\ Tiegang $^{4, e}$, KANG Bingjie ${ }^{4, f}$, \\ ${ }^{1}$ CPI Science and Technology Research Institute, No. 15 North Andeli Street, Dongcheng District, \\ Beijing, 100011, China \\ ${ }^{2}$ College of Materials Science and Engineering, Jilin University, No.5988 Renmin Street, \\ Changchun, 130022 China \\ ${ }^{3}$ Electric Power Research Institute of JLEP, No.4433 Renmin Street, Changhun, Jilin 130021, China \\ ${ }^{4}$ Training Center of JLEP,.No. 1427 Pingquan Road, Changchun, Jilin, 130021, China

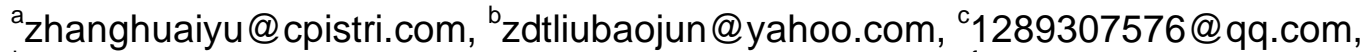 \\ 'wanghaijun@163.com, ${ }^{\mathrm{e}}$ cuitiegang195600@sohu.com, ${ }^{\dagger}$ 1548324871@qq.com
}

Keywords: magnetic property, TP347H, high temperature oxidation, VSM,SC units

Abstract. The saturated magnetization and coercive force of TP347H tube from SC units and is temperature oxidation have been measured by vibration specimen magnetometer. The oxidation has higher Ms and lower Hc compared with the base metal of TP347H. The basic difference of the oxidation and the stainless tube is be used for detecting the amount of oxidation in the inner side of the TP $347 \mathrm{H}$ tubes.

\section{Introduction}

SC and USC units are constructed and operated in China since 1980s with its advantages of high efficiency and low emission. Cr-Ni serials austenite stainless steel is widely applied in super-heaters and re-heaters of large scale boilers due to high thermal strength and anti-oxidation abilities. The microstructures of the steels under high temperature is steady, which meets the operation requirement[1-5]. SA213 TP347H is widely used as heating tubes for SC and USC units.

The operation practices show that oxidation exists in the inner side of heating tubes. The physical properties of steam oxidation are different with the base metal materials, especially the linear expansion co-efficiency. The oxidation will drop off during boiler starting or shutting down. Schikorr[6] first proposed the mechanism of austenite materials steam oxidation theory. Iron and steam react and produce $\mathrm{Fe}_{3} \mathrm{O}_{4}$ and $\mathrm{H}_{2}$ under $450^{\circ} \mathrm{C}$ no-oxygen steam environment.

The oxidation will accumulated in the U shape bend of the heating tubes and cause the following harms.

1 heating tube bursting caused by overheating induced by oxidation accumulation

2 damaging the main steam valve

3 destroying the turbine parts [7]

4 blocking the main steam valve

5 reduce the heat exchanging efficiency

6 degrading the water and steam quality

With the increasing of electricity consumption, the maintain period is decreasing, so it is necessary to carry out a quick austenite tube oxidation examination method. In this paper we carried out research on the magnetic properties of the base metal and oxidation of TP $347 \mathrm{H}$. 


\section{Experiments and materials}

The materials for experiment are TP $347 \mathrm{H}$ tube and the oxidation in the inner side of the tube from a $600 \mathrm{MW} \mathrm{SC}$ unit. The working temperature is about $570^{\circ} \mathrm{C}$, Specimen 1 has served for about 20000 hours, specimen 2 has served for 10000 hours and specimen 3 is a new tube. Specimen 4 is the oxidation from inner side of the tube of specimen 1.

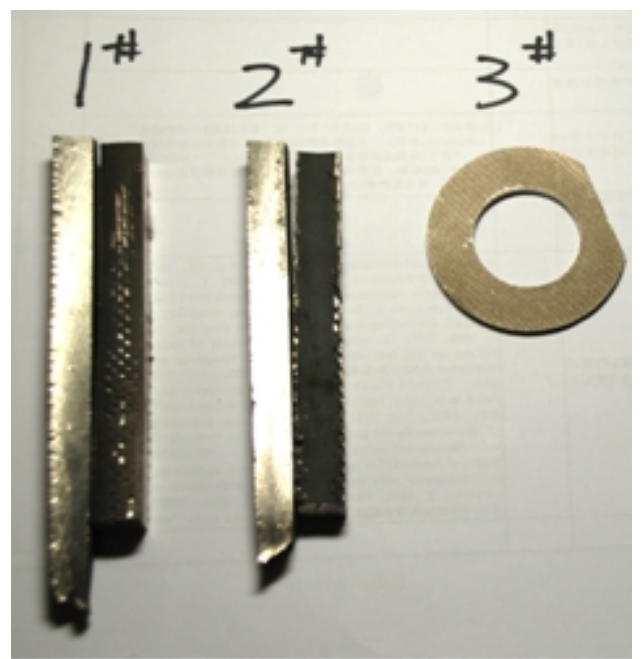

Fig. 1 TP347H specimens

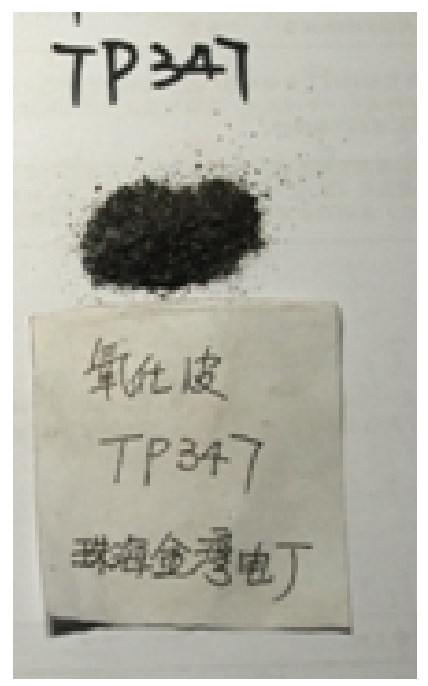

Fig. 2 Oxidation specimen 4

Fig.1 shows the testing materials ad its numbers.

The composition of TP $347 \mathrm{H}$ refers to table 1 .

Table 1. Chemical composition of TP347H [W\%]

\begin{tabular}{r|c|c|c|c|c|c|c}
\hline $\mathrm{C}$ & $\mathrm{Mn}$ & $\mathrm{Si}$ & $\mathrm{Cr}$ & $\mathrm{S}$ & $\mathrm{P}$ & $\mathrm{Ni}$ & $\mathrm{Nb}$ \\
\hline 0.07 & 1.5 & 0.5 & 18.2 & 0.002 & 0.02 & 11.5 & 0.8 \\
\hline
\end{tabular}

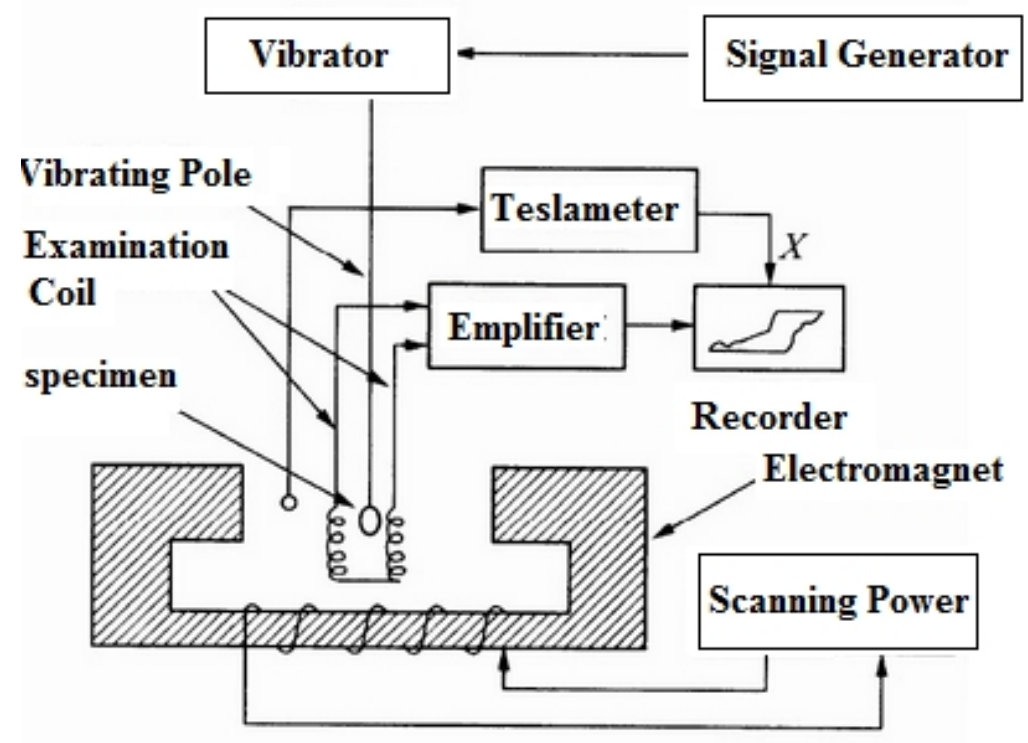

Fig.3 Principle of vibrating specimen magnetometer 


\section{Measuring principle of vibration specimen magnetometer}

Fig.3 indicates a vibrating specimen magnetometer(VSM) which is based of the electromagnetic induction principle. Small size specimen is used for the VSM, which is considered as a magnetic dipole from far distance when magnetized. So the vibration of the sample is regarded as the vibration of the field of a magnetic dipole. The magnetic flux in the examination coil near the specimen will vary which induces inducted electromagnetic potential in direct proportion to magnetization. Then calibrating with standard sample with given saturation magnetization, the saturated magnetization $\mathrm{Ms}$ and coercive force Hc etc. of the measured sample could be measured.

\section{Results and analyses}

The measuring results refer to Fig. 4a-d. The main magnetic indices are list in table 2. From Fig.4 it could be seen that all the 3 specimens show certain magnetism. The saturated magnetization of specimen 1 reaches $24.7 \mathrm{emu} / \mathrm{g}$ and specimen 2 reaches only $9.6 \mathrm{emu} / \mathrm{g}$. Specimen 3 reaches 15.9 $\mathrm{emu} / \mathrm{g}$, which is between specimen 1 and 2 . When oxidation appears in the austenite tube, the soft magnetization increases, which displays in two aspects, one is the saturated magnetization Ms increases and the other is that coercive force Hc decreases. Static magnetic conductivity is obtained after differential, refers to Fig 5. From table 2 it could be seen that the Ms of the base metal is between 1 and 2emu/g, however the Ms of oxidation is from 4 to $7.2 \mathrm{emu} / \mathrm{g}$. So the oxidation could be detected by magnetic methods. The measuring in this paper provides theoretical bases for future examination.

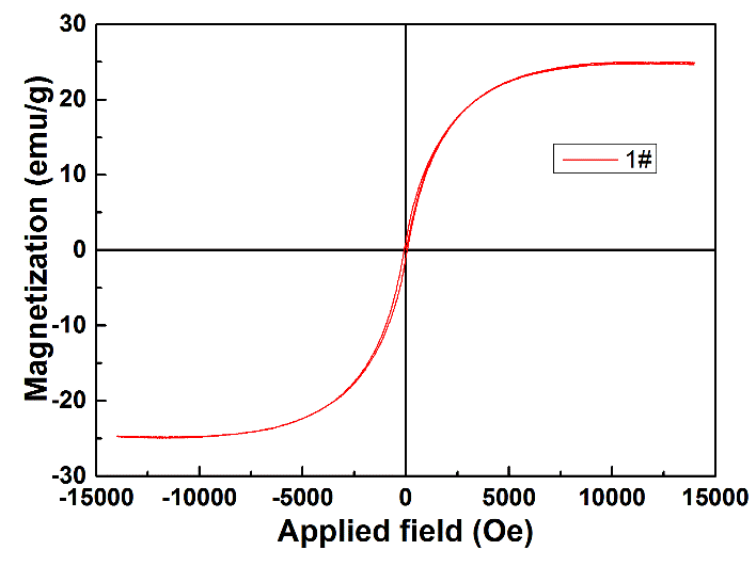

a specimen 1

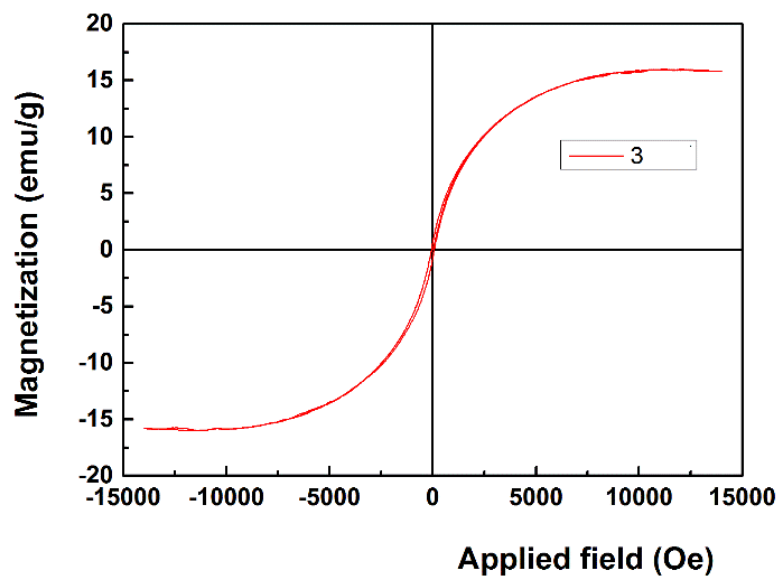

c specimen 3

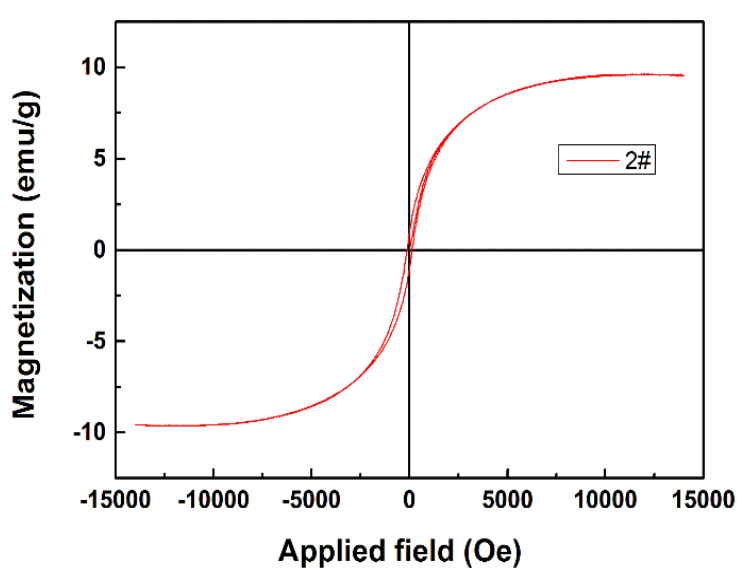

b specimen 2

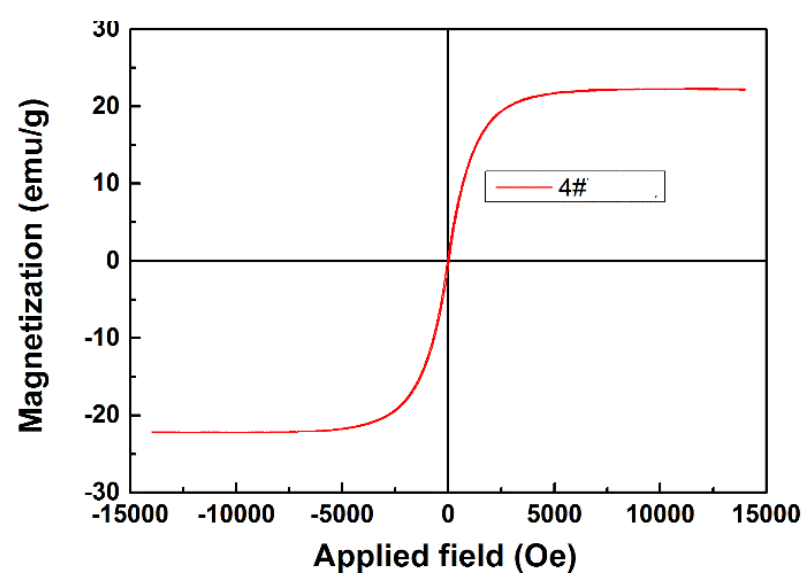

d specimen 4

Fig 4.magnetic hysteresis loop of specimen 1-4 


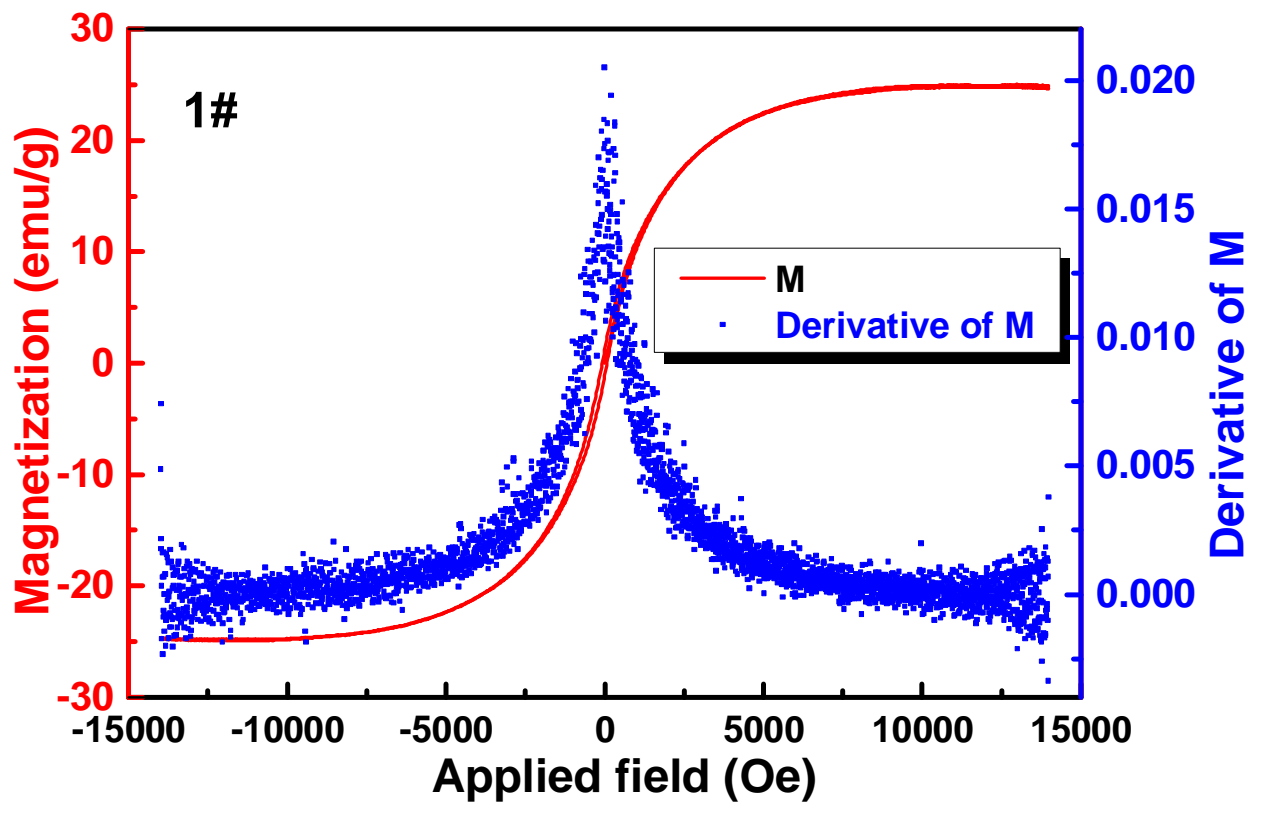

Fig 5. Magnetic hysteresis loop and differential curve for maximum static magnetic conductivity

Table 2. Measuring results

\begin{tabular}{c|c|c|c}
\hline Specimen & $\mathrm{M}_{\mathrm{S}}[\mathrm{emu} / \mathrm{g}]$ & $\mathrm{H}_{\mathrm{C}}[\mathrm{Oe}]$ & $\mu_{S}$ \\
\hline 1 & 24.7 & 74.5 & 2.0 \\
\hline 2 & 9.6 & 128.9 & 1.1 \\
\hline 3 & 15.9 & 67.5 & 1.8 \\
\hline 4 & 21.2 & 21.2 & 4.0 \\
\hline
\end{tabular}

\section{Conclusions}

1The base metal of TP $347 \mathrm{H}$ shows certain Ms and Hc, no matter the new one or after operation for certain hours;

2 The oxidation of TP347H has higher Ms and lower Hc compared with the base metal of TP 304H, which means that the oxidation of TP $304 \mathrm{H}$ is ferromagnetic material;

3 Non-destructive testing of oxidation in the inner side of the TP $347 \mathrm{H}$ tubes and the base metal could be carried out based on the large difference of Ms and lower Hc between TP347H and its oxidation.

\section{References}

[1] Xu Tongmo, Yi Chao, Chen Ganjin, Shao Guozhen.The Development Trend of Large Capacity USC Boiler [J]. Dynamic Engineering, 2003 (06):63-69.

[2] Huang Ying, Hua Hongyuan, Li Tao, Zhang Zhenxing. The Development and Key Issues of Large Capacity USC Boiler [J]. Power Generation Equipment, 2003,(01):15 - 17.

[3] Emsperger, Feldmuller. Status and Development of Power with High Supercritical Conditions[J]. Proc of Int Conf on Power Engineering, Vol11. 2001,612-622.

[4] Zhao Chengzhi, Wei Shuangsheng, GaoYalong. The Research Progress of Heating Resistance Steel for SC and USC Units [J]. Steel and Iron. 2007(09):35-39 
[5] Zhou Rongcan, Fan Changxin. The Research and Selection of USC Unit Materials [J]. China Power, 2005(08):41-46.

[6] R.B. Dooley, Opening remarks at the EPRI-NPL Workshop on Scale Growth and Exfoliation in Steam Plant, National Physical Laboratory, Teddington, England, Sept. 3-5, 2003

[7] Viswanathan R, Sarver J, Tanzosh J M. Boiler materials for ultra-supercritical coal power plants-steam side oxidation [J]. Journal of Materials Engineering and Performance, 2006, 15(3):255-274. 